Article

\title{
Correlations and Scalability of Mechanical Properties on the Micro, Meso and Macro Scale of Precipitation-Hardenable Aluminium Alloy EN AW-6082
}

\author{
Anastasiya Toenjes $1,2, * \mathbb{C}$, Heike Sonnenberg ${ }^{1,2} \mathbb{D}^{-}$and Axel von Hehl ${ }^{1,2,3}$ \\ 1 Leibniz Institute for Materials Engineering-IWT, Badgasteiner Str. 3, 28359 Bremen, Germany; \\ sonnenberg@iwt-bremen.de (H.S.); vonhehl@iwt-bremen.de (A.v.H.) \\ 2 Faculty of Production Engineering, University of Bremen, Badgasteiner Straße 1, 28359 Bremen, Germany \\ 3 MAPEX Center for Materials and Processes, University of Bremen, Bibliothekstr. 1, 28359 Bremen, Germany \\ * Correspondence: toenjes@iwt-bremen.de; Tel.: +49-421-218-51491
}

Received: 7 April 2020; Accepted: 6 May 2020; Published: 8 May 2020

\begin{abstract}
The mechanical properties of heat-treatable aluminium alloys are improved and adjusted by three different heat treatment steps, which include solution annealing, quenching, and aging. Due to metal-physical correlations, variations in heat treatment temperatures and times lead to different microstructural conditions with differences in the size and number of phases and their volume fraction in the microstructure. In this work, the investigations of the correlation between microhardness measurements on micro samples and the conventional mechanical properties (hardness, yield strength and tensile strength) of macro samples and the comparability of the different heat treatment states of micro and macro samples made of a hardenable aluminium alloy EN AW-6082 will be discussed. Using the correlations between the mechanical properties of micro samples and macro samples, the size of the samples and, thus, the testing cost and effort can be reduced.
\end{abstract}

Keywords: characterization methods; scalability; mechanical properties; aluminium alloys

\section{Introduction}

The mechanical properties of heat-treatable aluminium alloys are improved and adjusted by three different heat treatment steps, which include solution annealing, quenching and aging. Due to metal-physical correlations, variations in heat treatment temperatures and times lead to different microstructural conditions with differences in the size, the number of phases and the volume fractions in the microstructure. The resulting mechanical performance depends on the heat treatment parameters, and the material condition can be described in relation to the most often-preferred T6-condition, which reaches maximum hardness and strength values.

In the case that the mechanical properties of a new alloy need to be estimated fast, either modeling or experimental high-throughput characterization methods can be used. Most models for calculating the mechanical properties of precipitation-hardenable aluminium alloys after the heat treatment are based on metal-physical interrelations and require exact knowledge of the chemical composition of the alloy and the material conditions. The basis for calculating the changes in mechanical properties is information about the microstructure development of the heat-treated parts during the precipitation hardening. Therefore, many models require the parameters of the strength-enhancing phases such as size, number and/or distribution as input variables for the prediction of mechanical properties. The determination of the input variables requires experimental methods with high technical effort and specific sample preparation, such as small-angle X-ray scattering [1,2], small-angle neutron 
scattering [3], transmission electron microscopy [2-6] or differential scanning calorimetry [5,7]. In many cases, the basic equations of solid solution strengthening and precipitation hardening are used to calculate such mechanical properties as the yield, tensile strength and hardness [4,5,7-9]. As shown in Reference [10], the correlation between the Vickers hardness and tensile strength for the same material can also be determined accurately using a relatively simple relationship that depends on the quenching rate, aging temperature and aging time.

If the properties need to be characterized in a high-throughput method, the speed of both sample production and characterization must be increased. One way to reduce the processing time of different melts is to reduce the sample size. However, rapid material development means not only the rapid production of new alloys, such as rapid alloy prototyping [11], but also rapid material characterization [12]. A disadvantage of this is that many test methods such as tensile tests require a specific specimen geometry and size.

Within the Collaborative Research Center "Farbige Zustände" (CRC 1232) of the German Research Foundation (DFG), a novel high-throughput method for evolutionary structural material development is approached using micro samples $(<1 \mathrm{~mm})$ and adapted mechanical testing methods, which, therefore, reduces the testing cost and effort [13]. Microstructural changes as well as manufacturing influences on the material state of steel and aluminium materials are investigated. Spherical micro samples of different alloy compositions can be provided very quickly with droplet generators, as described in Reference [14], which enables both time-reduced and cost-reduced manufacturing of new types of alloys by using small batches. Many characterization methods of these samples have already been presented in Reference [15]. By combining results of different short-term characterization methods on micro samples such as the micro compression test [16], the potential of transferability from the micro to the macro scale regarding diverse material properties as strength, ductility and even machinability is increased.

The aim of this work is to investigate the correlation between microhardness measurements on micro samples and conventional mechanical properties, e.g., the tensile strength of macro samples, to reduce the testing cost and effort on the example of the conventionally used and well-known precipitation-hardenable aluminium alloy EN AW-6082. The scalability is investigated with the help of mid-range sized meso samples on which conventional testing (HV5 and tensile tests) can take place. Therefore, a direct connection can be drawn from the meso sample to the macro sample as well as from the meso sample to the micro sample since the universal microhardness (UMH) measurements can be performed on the micro level.

\section{Materials and Methods}

\subsection{Material and Sample Geometry}

All experimental investigations were performed on the aluminium alloy EN AW-6082. The chemical composition of the alloy was measured by glow discharge optical emission spectroscopy (GDOES) (MICA Analysen GmbH, Düsseldorf, Germany) and is presented in Table 1.

Table 1. Chemical analysis of the samples in wt.\% in comparison with the limitations of the DIN EN 573-3:2013-12.

\begin{tabular}{ccccccccc}
\hline \multirow{2}{*}{ Material } & & \multicolumn{7}{c}{ Chemical Composition in wt.\% } \\
\cline { 3 - 9 } & & Al & Si & Mg & Mn & Fe & Cu & Others \\
\hline Samples alloy & & bal. & 0.916 & 0.727 & 0.437 & 0.381 & 0.086 & $<0.05$ \\
\hline \multirow{2}{*}{ DIN EN 573-3:2013-12 } & min. & \multirow{2}{*}{ bal. } & 0.7 & 0.6 & 0.40 & - & - & - \\
& max. & & 1.3 & 1.2 & 1.0 & 0.50 & 0.10 & 0.15 \\
\hline
\end{tabular}


In this study, three different sample geometries are used (Figure 1): conventional tensile specimens, referred to as macro samples (a), flat specimens with a thickness of $2.5 \mathrm{~mm}$, referred to as meso samples (b) and spherical specimens with a diameter of $1 \mathrm{~mm}$, referred to as micro samples (c).

a)

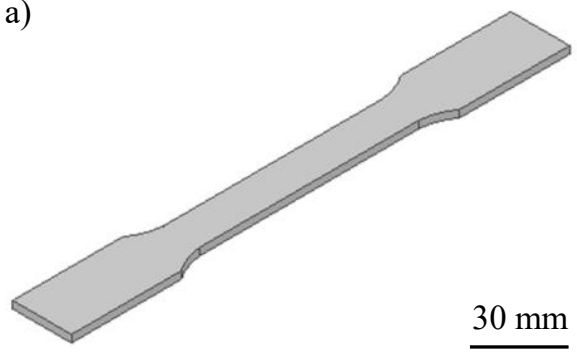

b)

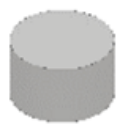

$5 \mathrm{~mm}$ c)

Figure 1. (a) Macro, (b) meso and (c) micro samples.

The flat tensile specimens with a length of $170 \mathrm{~mm}$ and small round samples with a diameter of $4 \mathrm{~mm}$ were both manufactured from rolled sheets in a T6 condition with a thickness of $2.5 \mathrm{~mm}$. The spherical micro samples were produced in a droplet generator. The micro cross-section of the samples before heat treatment can be seen in Figure 2. Figure 2a,b show a stretched microstructure typical for rolled sheets with more stretched grains in rolling direction. The micro samples show both a cellular and dendritic microstructure (Figure 2c).
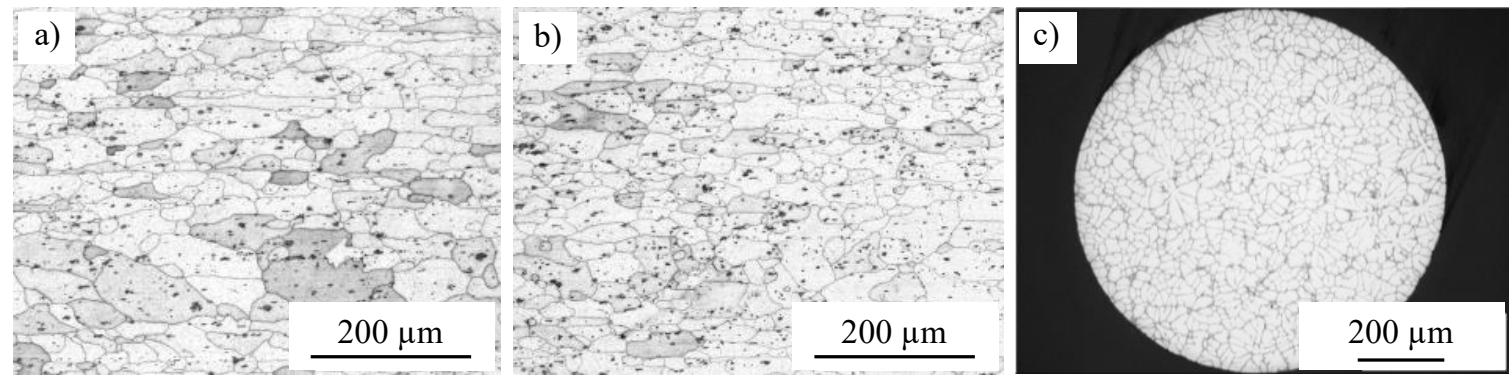

Figure 2. Micro cross-section of the macro and meso samples before the heat treatment in (a) a longitudinal to rolling direction, (b) transverse to rolling direction and (c) of the micro samples.

Due to the small sample size, micro and meso samples were prepared by embedding in a cold curing epoxy resin and grinding to an equatorial plane with water-cooled SiC abrasive paper (grit size of 320 to 1200). Before carrying out the tests, the surface of the samples was polished with a $1 \mu \mathrm{m}$ diamond suspension (roughness $S_{a}$ of $4-8 \mathrm{~nm}$ ).

\subsection{Heat Treatment}

In order to adjust the mechanical properties, precipitation hardening was applied. The design of the experiments was conducted using Cornerstone ${ }^{\circledR}$ software (version 7.1.0.2, camLine GmbH, Petershausen, Germany). The variation of heat treatment parameters was carried out according to the D-Optimal experimental design [17]. The advantages of a D-Optimal experimental design included significantly reduced experimental effort and maximum prediction power in the selected range of the parameters. The parameters of solution annealing temperature $\left(T_{\mathrm{s}}\right)$ and times $\left(t_{\mathrm{s}}\right)$ as well as aging temperature $\left(T_{\mathrm{a}}\right)$ and duration $\left(t_{\mathrm{a}}\right)$ were varied. Air, water and a polymer solution were used as quenching media (Table 2). With these three quenching media, slow cooling, fast quenching and a fast quenching with a reduction of the Leidenfrost [18] phenomenon could be achieved. During quenching in water, the samples were immersed in a circulated water bath at a temperature of approximately $20^{\circ} \mathrm{C}$. Polymer quenching took place in a similar way to water quenching. During air cooling, the samples were slowly cooled with an air blower. 
Table 2. Heat treatment parameters.

\begin{tabular}{|c|c|c|c|c|c|}
\hline No. & $T_{\mathrm{s}}\left({ }^{\circ} \mathrm{C}\right)$ & $t_{\mathrm{s}}(\mathrm{h})$ & $\mathbf{Q M}$ & $T_{\mathrm{a}}\left({ }^{\circ} \mathrm{C}\right)$ & $t_{\mathrm{a}}(\mathrm{h})$ \\
\hline 1 & 500 & 0.25 & Water & 100 & 20 \\
\hline 2 & 500 & 0.25 & Water & 240 & 2 \\
\hline 3 & 500 & 0.25 & Gas & 100 & 2 \\
\hline 4 & 500 & 0.25 & Gas & 170 & 11 \\
\hline 5 & 500 & 0.25 & Gas & 240 & 20 \\
\hline 6 & 500 & 0.25 & Polymer & 240 & 20 \\
\hline 7 & 500 & 2.13 & Polymer & 100 & 2 \\
\hline 8 & 500 & 4 & Water & 100 & 2 \\
\hline 9 & 500 & 4 & Water & 240 & 20 \\
\hline 10 & 500 & 4 & Gas & 100 & 20 \\
\hline 11 & 500 & 4 & Gas & 240 & 2 \\
\hline 12 & 500 & 4 & Polymer & 100 & 20 \\
\hline 13 & 500 & 4 & Polymer & 170 & 2 \\
\hline 14 & 530 & 0.25 & Polymer & 100 & 11 \\
\hline 15 & 530 & 2.13 & Gas & 170 & 20 \\
\hline 16 & 530 & 4 & Gas & 100 & 2 \\
\hline 17 & 530 & 4 & Polymer & 240 & 2 \\
\hline 18 & 560 & 0.25 & Water & 100 & 2 \\
\hline 19 & 560 & 0.25 & Water & 240 & 20 \\
\hline 20 & 560 & 0.25 & Gas & 100 & 20 \\
\hline 21 & 560 & 0.25 & Gas & 240 & 2 \\
\hline 22 & 560 & 0.25 & Polymer & 170 & 20 \\
\hline 23 & 560 & 0.25 & Polymer & 240 & 11 \\
\hline 24 & 560 & 2.13 & Polymer & 240 & 11 \\
\hline 25 & 560 & 4 & Water & 100 & 20 \\
\hline 26 & 560 & 4 & Water & 240 & 2 \\
\hline 27 & 560 & 4 & Gas & 100 & 11 \\
\hline 28 & 560 & 4 & Gas & 240 & 20 \\
\hline 29 & 560 & 4 & Polymer & 100 & 2 \\
\hline 30 & 560 & 4 & Polymer & 240 & 20 \\
\hline
\end{tabular}

With the selected parameters not only T6, but also overaged and underaged heat treatment conditions were reached. All these heat treatment states were characterized in Reference [10] with differential scanning calorimetry.

\subsection{Experimental Testing}

After the heat treatment of the samples, different experimental tests were carried out. In quasi-static tensile tests, the tensile strength $\left(R_{m}\right)$ and yield strength $\left(R_{p 0.2}\right)$ were measured on the macro samples. On both macro and meso samples, Vickers hardness measurements (HV5) were carried out. Universal micro hardness (UMH) measurements were conducted on meso and micro samples.

For the quasi-static tensile tests of the macro samples, a servo-hydraulic testing machine of the type PC 160M (Schenck, Darmstadt, Germany) was used. The tests were carried out according to DIN EN 6892-1 at a displacement rate of $1 \mathrm{~mm} / \mathrm{min}$ using strain gauges of the type FCA-2-23 (Preusser Messtechnik, Bergisch Gladbach, Germany) to determine the yield strength $R_{p 0.2}$ at a $0.2 \%$ strain. Three macro samples of the same heat treatment condition were examined.

The Vickers hardness measurements were conducted according to DIN EN ISO 6507-1 on a hardness testing device of the type LV-700AT (LECO Corporation, St. Joseph, MI, USA) with a load of $5 \mathrm{kp}$ (HV5). For the Vickers hardness testing, the repetition of the experiment varied due to the sample size and required spacings of indentations. There were five hardness measurements done on each macro sample $(\mathrm{N}=5)$ and only one measurement on each meso sample $(\mathrm{N}=1)$ since these meso samples were too small for further indentations. However, three macro and meso samples of the same heat treatment condition were used to calculate the mean values. 
The universal hardness measurements were performed on a Fischerscope H100C testing device (Helmut Fischer GmbH, Sindelfingen, Germany) using a Vickers indenter and a maximum indentation force of $200 \mathrm{mN}$. The loading time, holding time and relief time were set to $10 \mathrm{~s}$ each. There were 25 individual measurements carried out on each sample while investigating three meso and micro samples in each heat treatment condition. Therefore, there were 75 measurements in total for each condition. In the following, the indentation hardness (HIT 0.2/10/10/10) is used as a characteristic value of UMH measurements for further comparison.

\section{Results and Discussion}

The aim of this work is to find correlations between mechanical properties of micro samples and macro samples. The scalability is investigated with the help of mid-range sized meso samples on which conventional hardness testing (HV5) can take place. Therefore, a direct connection can be drawn from the meso sample to macro sample as well as from the meso sample to micro sample since the $\mathrm{UMH}$ measurements can be performed on a micro sample. Figure 3 shows the measured hardness of macro samples when compared to the hardness of meso samples. Only those heat treatment states were further investigated, which exhibited a hardness deviation between the macro samples and meso samples of less than $\pm 10 \%$.

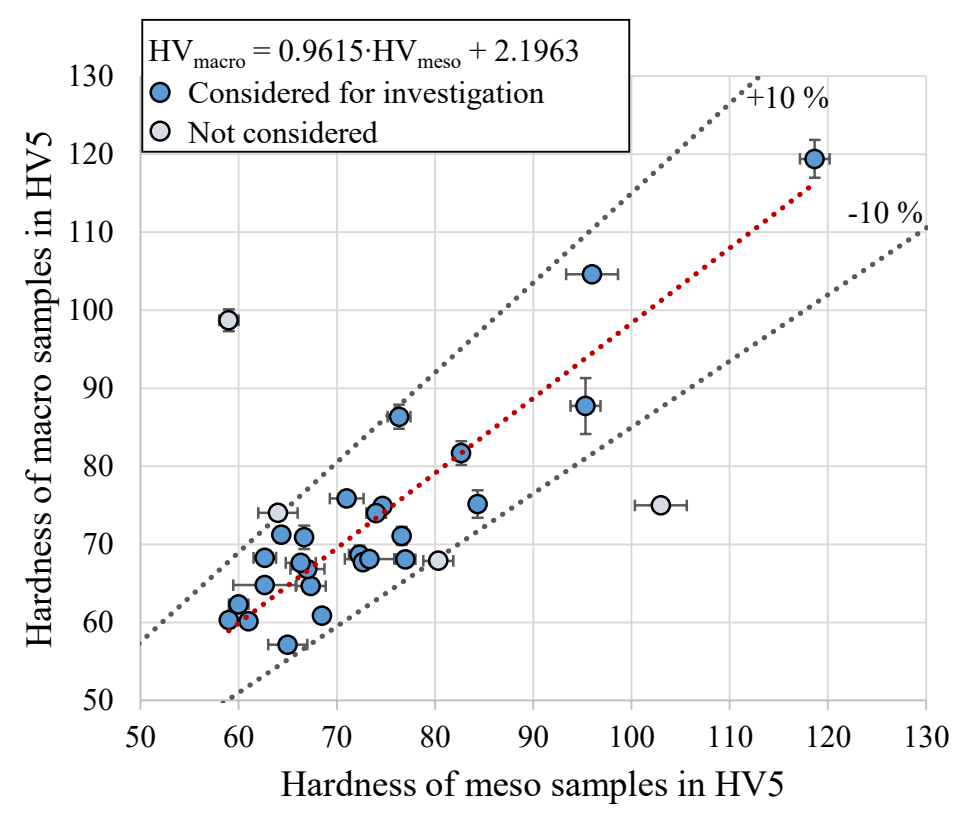

Figure 3. Correlation between hardness of macro and meso samples.

In order to determine the correlation between macro and micro samples, the correlation between the hardness and indentation hardness of meso samples is first investigated (Figure 4). 


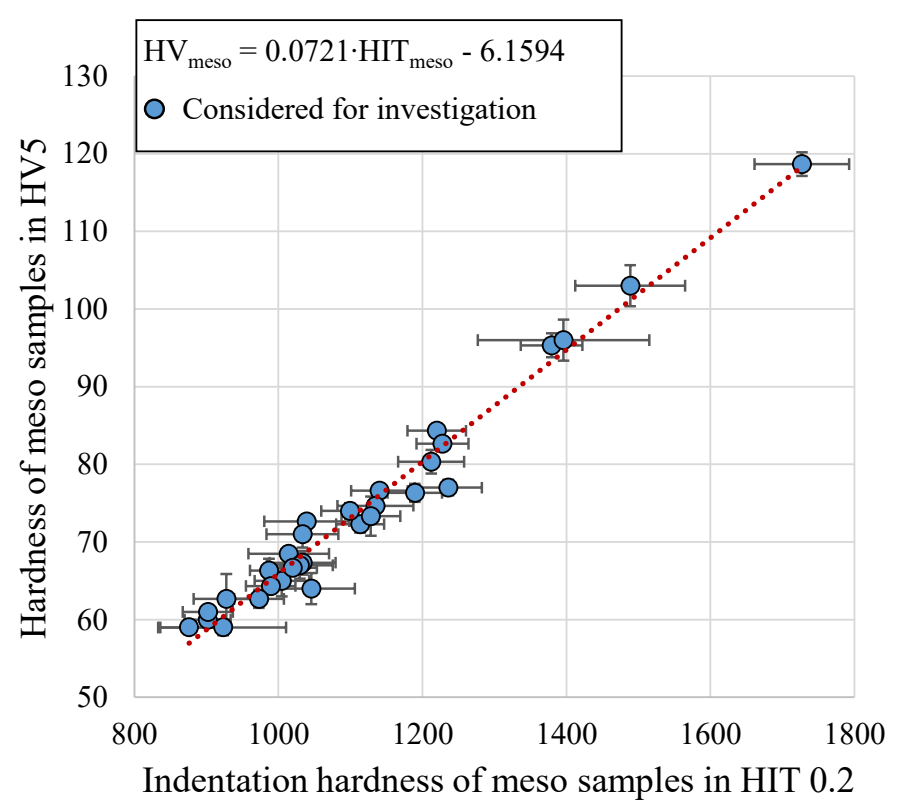

Figure 4. Correlation between the hardness and indentation hardness of meso samples.

The correlation between the indentation hardness of meso and micro samples is shown in Figure 5. In the same way as for the hardness of macro and meso samples, only those heat treatment states were further investigated, which had a hardness deviation between the meso and micro samples of less than $\pm 10 \%$.

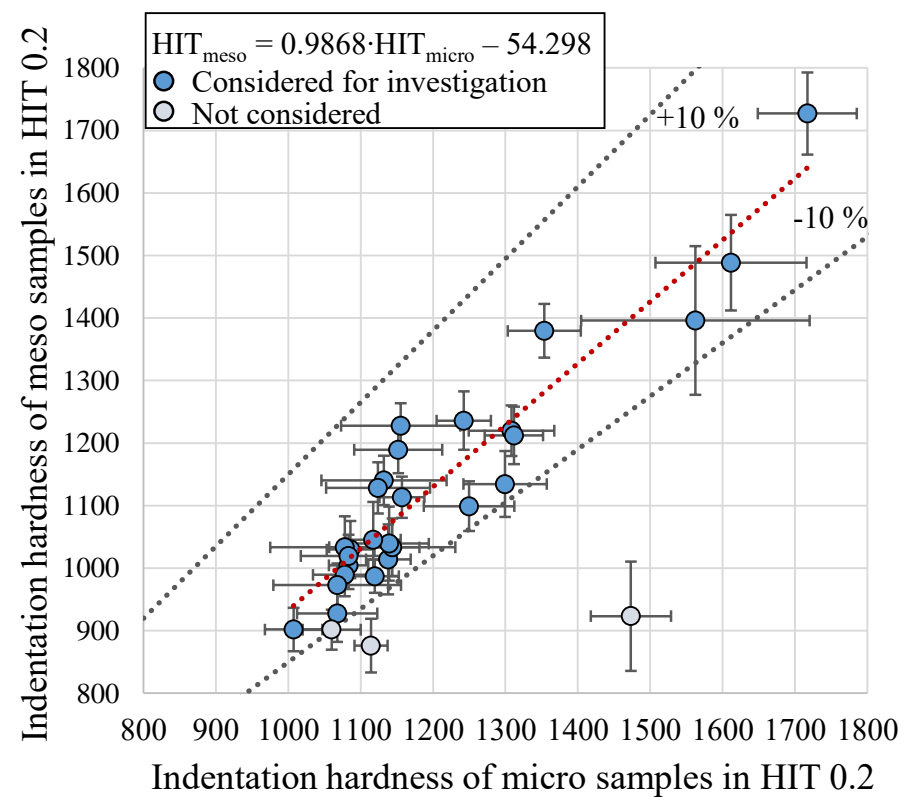

Figure 5. Correlation between indentation hardness of meso and micro samples.

Thus, the correlations between the indentation hardness of the micro samples and the indentation hardness of the meso samples, correlation between the indentation hardness of the meso samples and the hardness of the meso samples and correlation between the hardness of the meso samples and the hardness of the macro samples were established (Figure 6). 
Figure 3

Figure 4

Figure 5

\begin{tabular}{|c|c|c|c|}
\hline $\begin{array}{c}\text { Macro } \\
\text { HV5 }\end{array}$ & $\begin{array}{c}\text { Meso } \\
\text { HV5 }\end{array}$ & $\begin{array}{c}\text { Meso } \\
\text { HIT } 0.2\end{array}$ & $\begin{array}{c}\text { Micro } \\
\text { HIT } 0.2\end{array}$ \\
\hline
\end{tabular}

Correlation between micro and macro samples

Figure 6. Schematic overview on investigated correlations between micro, meso and macro samples based on conventional hardness (HV5) and indentation hardness (HIT 0.2).

The equation for calculating the hardness of macro samples using the measurements of the indentation hardness on the micro samples is, therefore, as follows.

$$
H V_{\text {macro }}=0.0683 \cdot H I T_{\text {micro }}-7.4901
$$

The hardness calculated with Equation (1) as well as the measured hardness are summarized in Figure 7. Although the sample size and microstructure were different, a good accordance between the calculated and measured hardness was achieved. The deviations were due to the individual measuring methods on the one hand and to the differences in the heat treatment conditions on the other hand. The macro, meso and micro samples were heat-treated with the same parameters, but the small samples cooled down faster when compared to the large samples, which may have affected the final properties. The data points excluded in Figures 3 and 5 were not considered in the calculation of the coefficient of determination.

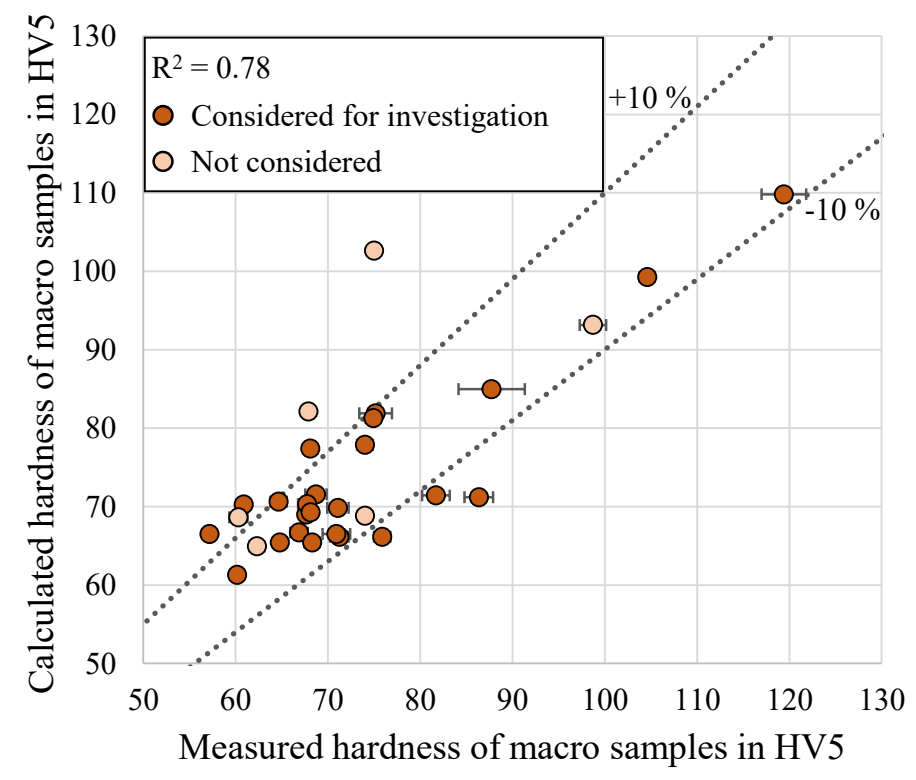

Figure 7. Calculated and experimental data for the hardness of macro samples.

The correlation between hardness and tensile strength as well as the yield strength can be seen in Figures 8 and 9 . 


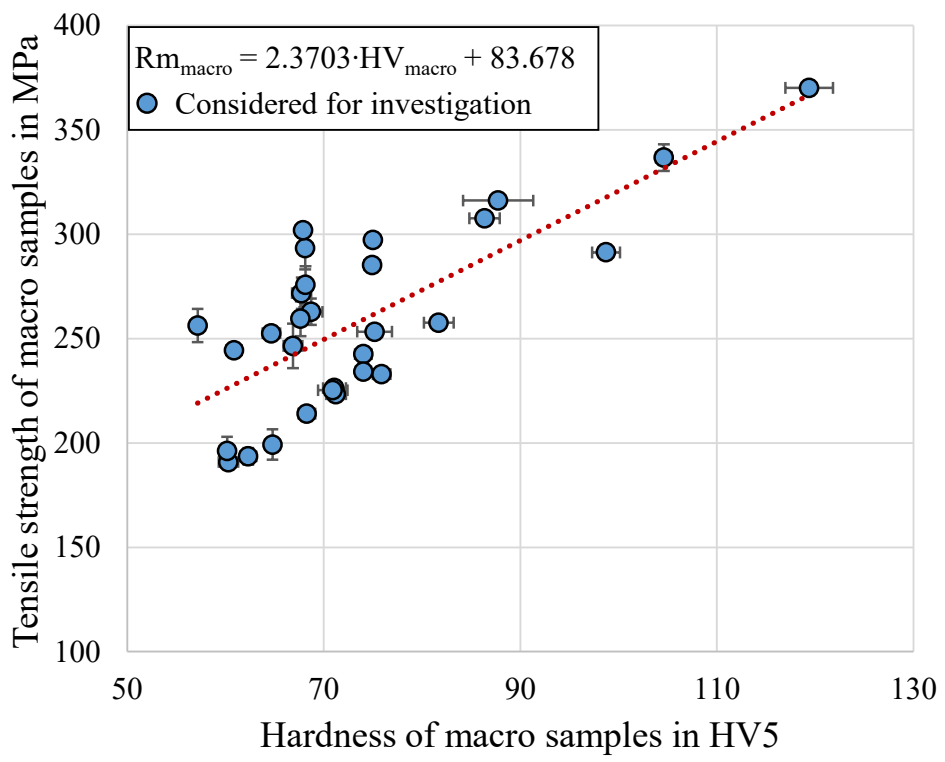

Figure 8. Correlation between tensile strength and hardness of macro samples.

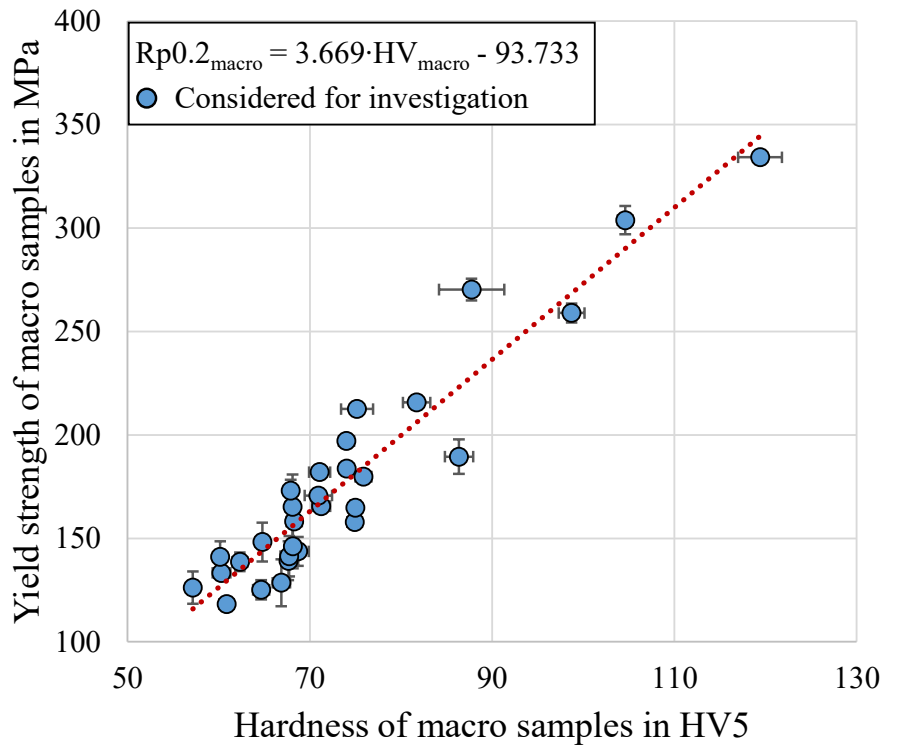

Figure 9. Correlation between yield strength and hardness of macro samples.

The tensile strength and yield strength were calculated with the correlations determined in Figures 8 and 9. The hardness was calculated using Equation (1). The results were summarized in Figures 10 and 11. It was, thus, possible to demonstrate that the tensile strength and the yield strength can be predicted based on the indentation hardness, measured on micro samples, even though the macro and micro samples were manufactured in a different way with resulting differences in the microstructure. In the same way as for the calculation of hardness, the data points excluded in Figures 3 and 5 were not considered in the calculation of the coefficient of determination. 


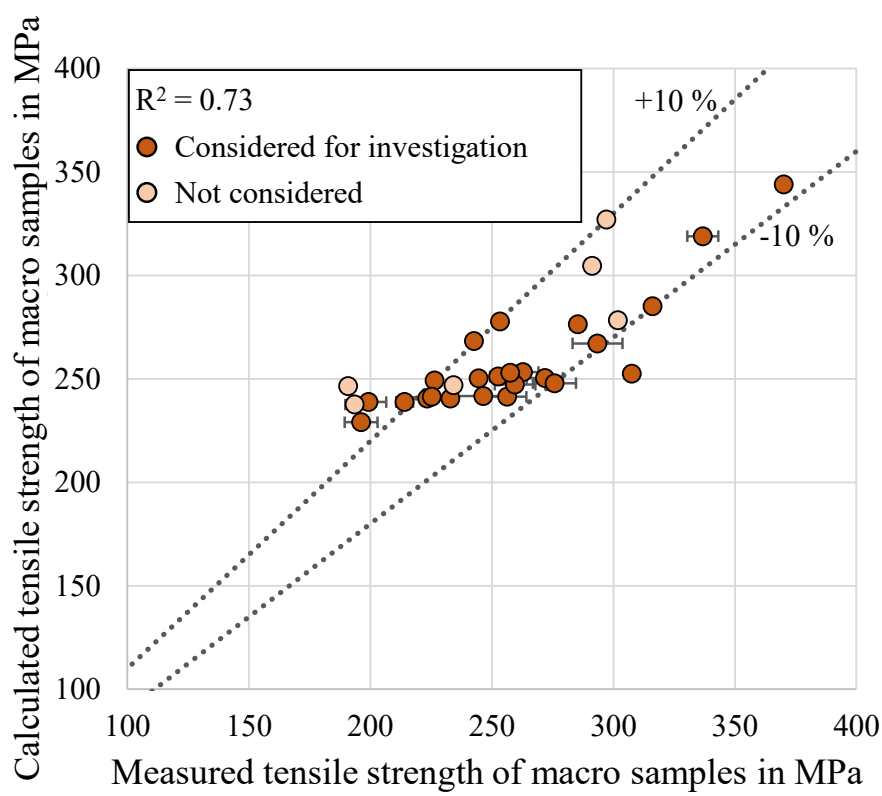

Figure 10. Calculated and experimental data for the tensile strength of macro samples.

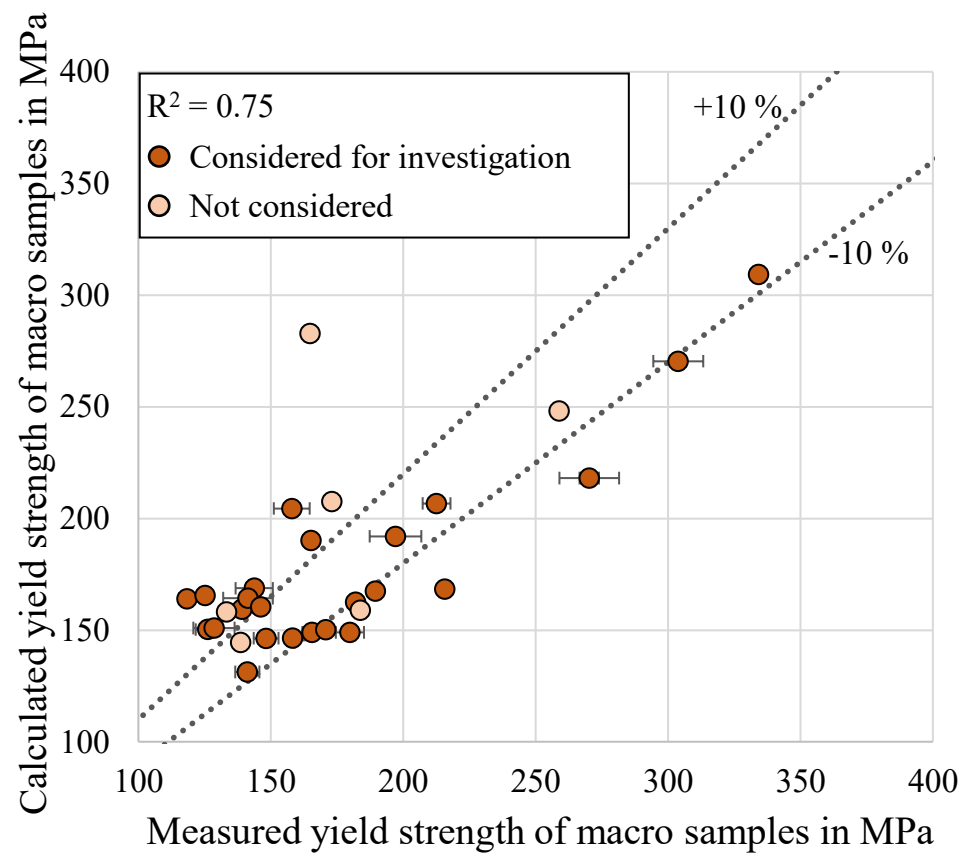

Figure 11. Calculated and experimental data for the yield strength of macro samples.

\section{Conclusions}

In this paper, a method for the fast and relatively accurate calculation of mechanical properties after heat treatment (i.e., solution annealing, quenching and ageing) was presented using the example of an age-hardenable aluminium alloy based on indentation hardness measurements on micro samples. Using mid-range sized meso samples on which conventional hardness (HV5) and indentation hardness measurements could be performed, a connection between the results of micro samples and macro samples could be established, which allows a direct investigation of the scalability. It was demonstrated that, despite different production routes and microstructures, the micro samples have a similar hardness to the meso and macro samples. 
To evaluate this approach, the coefficient of determination was calculated for the correlation between hardness (HV5) and indentation hardness (HIT 0.2/10/10/10) on a micro scale, which results in $R^{2}=0.78$. Furthermore, a coefficient of determination of 0.73 for the tensile strength and 0.75 for the yield strength was calculated. Therefore, the results of this calculation method on the example of the aluminium alloy EN AW-6082 show the potential of predicting mechanical properties by using fast and resource-efficient producible micro samples. The transfer of this method to other alloys remains to be evaluated.

Author Contributions: A.T. performed all experiments, analyzed the obtained data, and wrote the paper with the aid of H.S. in questions of UMH. A.v.H. supervised all investigations, and supported the work with his scientific knowledge. All authors have read and agreed to the published version of the manuscript.

Funding: This research was funded by The German Research Foundation (DFG), Deutsche Forschungsgemeinschaft, grant number: 276397488.

Acknowledgments: Financial support of subprojects U03 "Thermal and thermomechanical heat treatment" and D01 "Qualification of material conditions with mechanical and physical measuring methods" of the Collaborative Research Center CRC 1232 by the Deutsche Forschungsgemeinschaft (DFG, German Research Foundation)-project number 276397488-SFB 1232 is gratefully acknowledged.

Conflicts of Interest: The authors declare no conflict of interest.

\section{References}

1. Nicolas, M.; Deschamps, A. Characterisation and modelling of precipitate evolution in an Al-Zn-Mg alloy during non-isothermal heat treatments. Acta Mater. 2003, 51, 6077-6094. [CrossRef]

2. Werenskiold, J.C.; Deschamps, A.; Brechet, Y. Characterization and modeling of precipitation kinetics in an Al-Zn-Mg alloy. Mater. Sci. Eng. 2000, A293, 267-274. [CrossRef]

3. Bardel, D.; Perez, M.; Nelias, D.; Deschamps, A.; Hutchinson, C.R.; Maisonnette, D.; Chaise, T.; Garnier, J.; Bourlier, F. Coupled precipitation and yield strength modelling for non-isothermal treatments of a 6061 aluminium alloy. Acta Mater. 2014, 62, 129-140. [CrossRef]

4. Esmaeili, S.; Lloyd, D.J. Modeling of precipitation hardening in pre-aged $\mathrm{AlMgSi}(\mathrm{Cu})$ alloys. Acta Mater. 2005, 53, 5257-5271. [CrossRef]

5. Khan, I.N.; Starink, M.J.; Yan, J.L. A model for precipitation kinetics and strengthening in Al-Cu-Mg alloys. Mater. Sci. Eng. 2008, A472, 66-74. [CrossRef]

6. Österreicher, J.A.; Papenberg, N.P.; Kumar, M.; Ma, D.; Schwarz, S.; Schlögl, C.M. Quantitative prediction of the mechanical properties of precipitation-hardened alloys with special application to Al-Mg-Si. Mater. Sci. Eng. A 2017, 703, 380-385. [CrossRef]

7. Sepehrband, P.; Esmaeili, S. Application of recently developed approaches to microstructural characterization and yield strength modeling of aluminum alloy AA7030. Mater. Sci. Eng. A 2008, 487, 309-315. [CrossRef]

8. Esmaeili, S.; Lloyd, D.J.; Poole, W.J. A yield strength model for the Al-Mg-Si-Cu alloy AA6111. Acta Mater. 2003, 51, 2243-2257. [CrossRef]

9. Zander, J.; Sandström, R. One parameter model for strength properties of hardenable aluminium alloys. Mater. Des. 2008, 29, 1540-1548. [CrossRef]

10. Toenjes, A. Empirische Methode zur schnellen Charakterisierung von Wärmebehandlungszuständen hochfester Aluminiumlegierungen. Ph.D. Thesis, Universität Bremen, Bremen, Germany, 2019.

11. Springer, H.; Raabe, D. Rapid alloy prototyping: Compositional and thermo-mechanical high throughput bulk combinatorial design of structural materials based on the example of $30 \mathrm{Mn}-1.2 \mathrm{C}$-xAl triplex steels. Acta Mater. 2012, 60, 4950-4959. [CrossRef]

12. Potyrailo, R.; Rajan, K.; Stoewe, K.; Takeuchi, I.; Chisholm, B.; Lam, H. Combinatorial and high-throughput screening of materials libraries: Review of state of the art. ACS Combinatorial Sci. 2011, 13, 579-633. [CrossRef] [PubMed]

13. Ellendt, N.; Mädler, L. High-Throughput Exploration of Evolutionary Structural Materials. HTM J. Heat Treat. Mater. 2018, 73, 3-12. [CrossRef]

14. Moqadam, S.I.; Madler, L.; Ellendt, N. Microstructure Adjustment of Spherical Micro-samples for High-Throughput Analysis Using a Drop-on-Demand Droplet Generator. Materials 2019, 12, 3769. [CrossRef] [PubMed] 
15. Steinbacher, M.; Alexe, G.; Baune, M.; Bobrov, I.; Bösing, I.; Clausen, B.; Czotscher, T.; Riemer, O.; Sonnenberg, H.; Thomann, A.; et al. Descriptors for High Throughput in Structural Materials Development. High-throughput 2019, 8, 22. [CrossRef] [PubMed]

16. Sonnenberg, H.; Clausen, B. Short-Term Characterization of Spherical 100Cr6 Steel Samples Using Micro Compression Test. Materials 2020, 13, 733. [CrossRef] [PubMed]

17. Box, G.E.P.; Lucas, H.L. Design of experiments in nonlinear situations. Biometrika 1959, 46, 77-90. [CrossRef]

18. Sarmiento, G.; Bronzini, C.; Canale, A.; Canale, L.; Totten, G. Water and Polymer Quenching of Aluminum Alloys: A Review of the Effect of Surface Condition, Water Temperature, and Polymer Quenchant Concentration on the Yield Strength of 7075-T6 Aluminum Plate. J. ASTM Int. 2008, 6, 1-18.

(C) 2020 by the authors. Licensee MDPI, Basel, Switzerland. This article is an open access article distributed under the terms and conditions of the Creative Commons Attribution (CC BY) license (http://creativecommons.org/licenses/by/4.0/). 